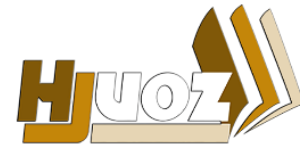

hjuoz.uoz.edu.krd p-ISSN: 2410-7557
كُوْارا زانستيّن مروّفايهتى يا زانكوّيا زاخوّ

مجلة العلوم الانسانية لجامعة زاخو

Humanities Journal of University of Zakho (HJUOZ)

Vol. 5, No. 1, pp. 402 - 413, March-2017

\title{
تقويم الذاتي للمشرفين التربويين والإداريين في مركز قضاء زاخو
}

\author{
بيوار طه شكري و نصرالدين ابراهيم محمد \\ قسم علم النفس العام، فاكولتي التربية، جامعة زاخو، إقليم كوردستان - العراق.
}

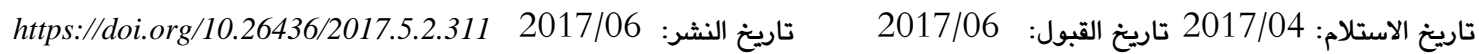

الملخص:

تهدف البحث الحالي التعرف على تقويم الذاتي للمشرفين التربويين والإداريين في مركز قضاء زاخو والتعرف على الفروق تبعا للمتغيرات

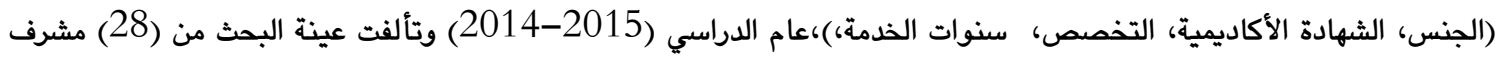

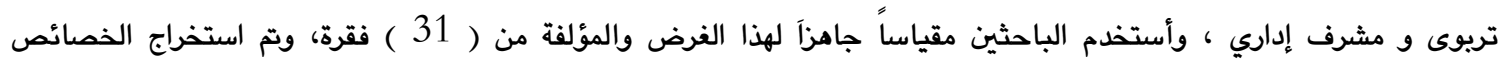

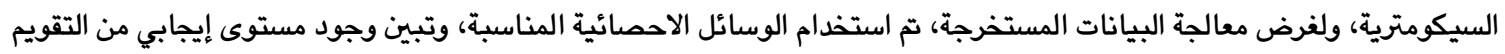
الذاتي للمشرفين و المشرفات التربويين و الإداريين، مع عدم وجد فروق ذات دلالة احصائية بين التقويم الذاتي لديهم وفقاً لمتغيرات الدراسة، وعلى ضوء ذلك قدم الباحثين مجموعة من التوصيات والمقترحات.

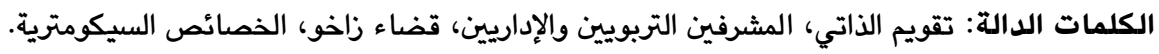

\section{1. أهمية البحث والحاجة اليه:}

تعد العملية التربوبة والتعلمية عاملاً هاماً في العمل الإنتاجي في أي الي التهاهي

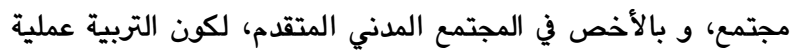

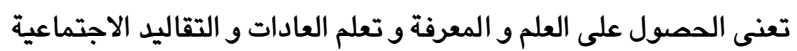
بهدف إعداد الفرد للحياة، كما و أن التربية و التعليم تواصلٍ العمل من أجل الدفع بحالة تربية المجتمع نحو الأحسن و الإفضل، فهي دائماً

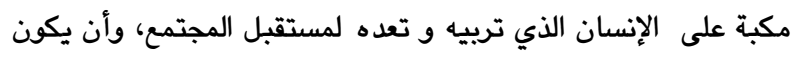

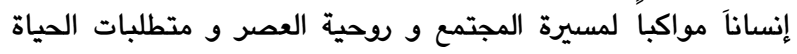
المعاصرة و الطبيعة السائدة (كةلهور، 2004: 86 ) واكيان يؤكد التربويين على مبدأ التقويم كعملية تعاونية يشترك فيها المتعلمون والمعلمون والمشرفين التريويين والموجهون الاداريون ومديري

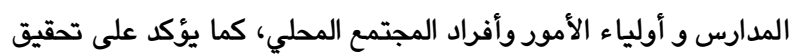
مبدأ التقويم الذاتي في العملية التربوية وخاصة في المراحل الاولية من

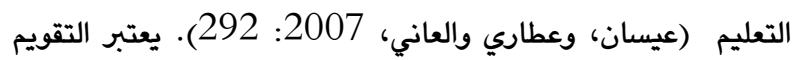
الذاتي من أصدق أنواع التقويم، حيث يعطي المشرف فرصة موضوعية الترانية لمراجة ممارساته التربوية بحرية، بحيث يقف على نواحي الظعف والقوة ويفكر فيها فيعدل السلبيات ويعزن الايجابيات ويعطي صورة يرى بها

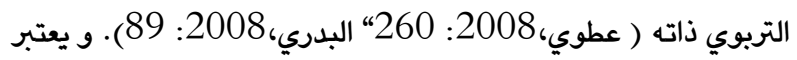
بعض التربويين اسلوب التقييم الذاتي أداة للتنمية الذاتية للمشرفين تتطلب منه وتجبره على التفكير في نقاط القوة والضعف لديه واقتراح سبل تحسين أدائه والمعايير لذلك ( البغدادي و العبادي،2010:

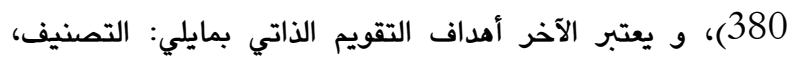

\section{1}

تواجة كثير من الأنظمة التربوية والتعليمية في العالم انتقادات حول قدرتها على المساممة في تنمية مجتمعاتها والنهوض بمستويات الطلبة معرفياً واجتماعياً ونفسياً، ولاشك ان هناك عوامل اجتماعية واقتصادية وسياسية تؤثر في الانظمة التربوية من حيث نجاحها أو قصورها أو أو هنال فشلها، وأن العلمية الإدارية في أي نظام لها دور كبير في نجاحه أو فشله (عابدين،2005: 12). والإحصائيات الرسمية حول نتائج الإمتحانات

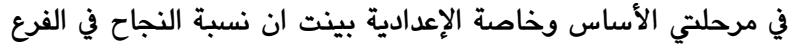

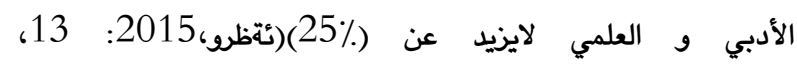

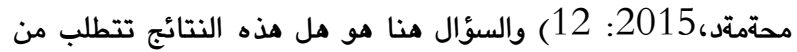
الجهات المعينة بالعلمية التعليمية مراجعة وتقويم ذواتهم لمعالجة مثل هذه الحالات؟ ومن جانب آخر ان ازدياد عدد المدارس ويما فيها

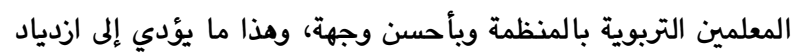
واجبات المشرفين، ومن هذا المنطلق جاء إحساس الباحثين بوجود هذه المشكلة وضرورة دراستها بشكل علمي من خلال التساؤلات

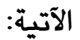
1- مامستوى التقويم الذاتي للمشرفين تربوي أم إداري في مركز قضاء زخو؟ 2- هل يوجد فرق بين التقويم الذاتي للمشرفين تربوي أم إداري في مركز قضاء زخو بحسب متغيرات (الجنس، الشهادة الأكاديمي،

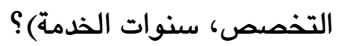


بين المشرفين التربويين و المدرسين و التلاميذ، مؤكداً على أن تكون هذه العلاقة قائمة على أساس ديمقراطي سليم، لأن المشرف التربوي

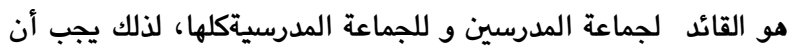
يقوم بدود القائد الناجع المدرك لوظائفه القيادة ( سرحان، 2003:206

ونتبع أهمية البحث الحالي بالنسبة للتربويين وذوي العلاقة من التربويين في إقليم كوردستان بصورة عامة، ومنطقة زاخو بصورة

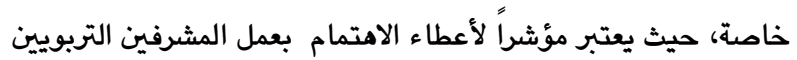

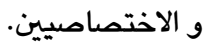

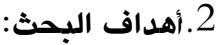

يهدف البحث الحالي إلى الإجابة عن السؤالين الآتين: 1 ـ مستوى التقويم الذاتي لدى المشرفين التربويين و الإداريين في مركز قضاء زاخو؟

2. هل هناك فروق ذات دلالة الإحصائية للتقويم الذاتي لدى المشرفين

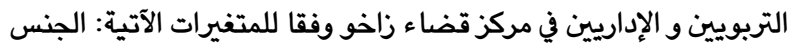
(ذكور- اناث)، الشهادة الأكاديمية ( دبلوم- بكالوريوس) التخصص

$$
\text { (علمي- ادبي)، سنوات الخدمة؟ }
$$

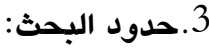

يقتصر حدود البحث الحالي على المشرفين التربويين و الإداريين في مركز قضاء زاخو للعام الدراسي (2015-2014). تعديد المصطلحات:تحددت المصطلحات التي تناولها البحث الحالي بالآتي:

1.3 التقويم الذاتي: وعرفه كل من:

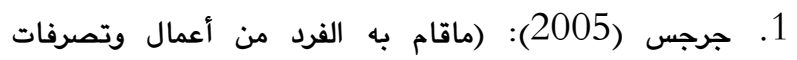

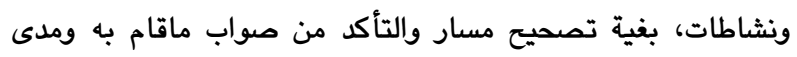
الإفادة التي انتجها له أو للآخرين).(جرجس،2005: 223). 2. حسان والعجمي(2007): يقصد التقويم الذاتي ( أن يقوم الإنسان ذاته بذاته يتعرف في ضوء هذا التقويم، فيعتبر بممارساته السليمة و

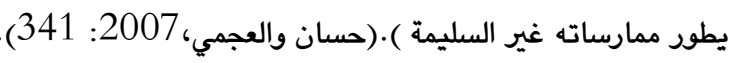
التعريف الاجرائي: ومما تقدم يعرف الباحثان التقويم الذاتي اجرائياً

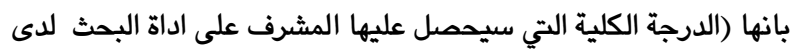
استجابته، على فقراته و تمثل الدرجة مستوى التقويم الذاتي لديها)

2.3 الإشراف التربوي: عرفها كل من: 1. كارتر كود (Good): بأنها جميع الجهود التي يبذلها القائمون على أمر التعليم بتوفير القيادة المطلوبة لتوجيه المعلمين من أجل

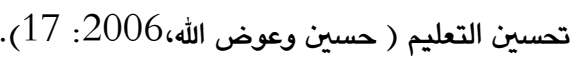

المحاسبة، التطوير التغذية الراجعه وذلك بصورة مستمرة داخل المؤسسة التعليمية ( حمادات، 2007: 305). لأهمية عملية الإثراف التربوي و تأثيرما على عمليتي التعليم و التعلم، يتفق كثير من الباحثين والمختصيين في التربية على أن الهدف العام الشامل للإثراف هو" تحسين عملية التعليم والتعلم" وأن الهدف

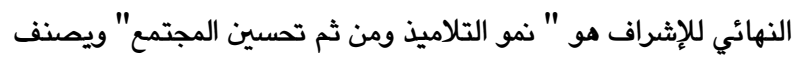
بورتون و بروكنر( Burton \& Bruckner) هدفين مهمين للاثراف التربوي مما:" تحقيق ضمان استمرارية البرنامج التربوي وإعادة تكيفة خلال فترة طويلة من الزمن، وتطوير بيئات مناسبة للتعليم والتعلم، كطرق التدريس والجو النفسي والاجتماعي و المادي

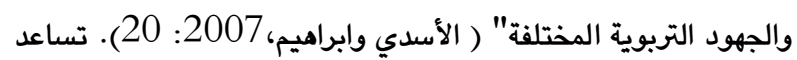
القيادة الإثرافية على تنمية القدرة على التقويم الذاتي و ذلك بوسائل مختلفة منها فرص الاتجاه نحو الموضوعية في معالجة المشكلات وتوفير المعلومات عن الظروف والأوضاع السائدة في المدرسة، ويناء روح معنوية عالية عن طريق إسهام المدرسين في التخطيط و وضع السياسة العامة للمدرسة، ويجب أن تتماشي مع الاتجاهات المعاصرة في التربية والتعليم. ( محمد، 2008: 130). نظراً لأممية الإثراف في نجاح عملية الإدارة التربوية وتحقيق أهدافها، يؤكد بعض التربويين و بنظرية الإختصاصيين في مجال الإدارة أمثال فريدريك هرزبرج ( F. Herzberg ) في نظريته الموسومة بالنظرية العوامل الدافعية الصحية على أن نمط الإثراف هو من العوامل ألتي

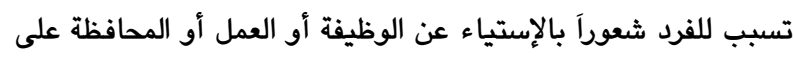

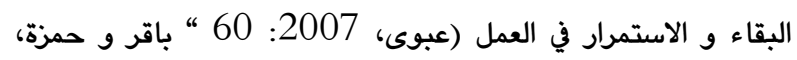

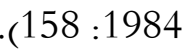

تعتبر زيارة المشرف التربوي للمدرسة والمعلم أو المدارس خلال قيامه

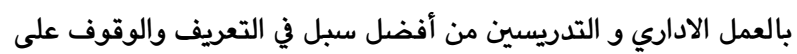
الصعويات ألتي يواجهم وطرق تذليلها في العملية التعليمية من خلال تقديم المساعدة لهم من قبل المشرف التربوي. لذلك يجب أن يتفهم المدرسون أن الزيارات الإثرافية لهم ليست وسيلة لبيان سلطته عليهم

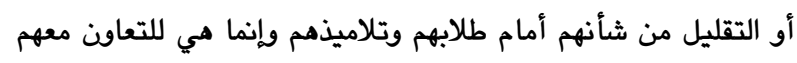
لخدمة الطلبة وذلك بالإستفاده من خبرات المشرف التعليمية في تحسين عملية التعلم والتعليم. ( البدري، 2008: 103)، و يعتبر كل من بارون و بايرن (Baron and Byrne ) علىَ أهمية و تأثير المشرف ولئ و أهتمامه بالحاجات و ميول المرؤسين و معاملته الجيدة و محاولة غرس الرضى الوظيفي لديهم كأحد من العوامل الرئيسية في نجاح

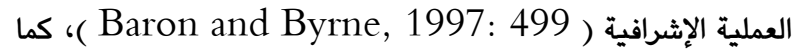
و يؤكد كيسلي ( Giselli ) على أهمية قدرات المشرف في التعامل مع المواقف المختلفة و متطلبات مذه المواقف و نجاح المؤسسة و التنظيم Ivancevich, Konopaskeand ) فيها في Matteson,2005:495 )، و يؤكد التريويين على أهمية العلاقة 
أساساً هي حصيلة تكتسب ببطء ويساعد على تعزيزها وتطوير تقويم المشرف لعمله وتعديله لأساليبه بإستمرار، المشرف التربوي، كأي إنسان، هناك جوانب من عمله يؤديها أداء حسناً، وهناك جوانب فيها بعض القصور والنقص، فعليه في هذه الحالة أن يكون صادقاً مع نفسه لتلاقي قصور وتصويب أخطائه ويذلك يكتسب المهارة ألتي تجعله

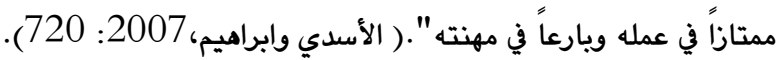
سلطات المشرف التربوي: يستمد المشرف التربوي سلطته ممايلي:

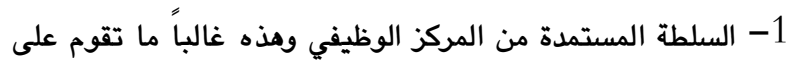
الثواب والعقاب وتستمد من المسؤولية الشرعية والقوانين و الأنظمة والتعليمات. 2- السلطة المستمدة من الخبرة الفنية والتفوق العملي وتقويم على حسن الأداء والإقناع العلمي باعتبار المشرف التربوي هو خبير في التعليم. 3- السلطة المستمدة من المجموعة غير الرسمية أو النقابات أو الأحزاب ويفضل أن يعتمد المشرف التربوي على السلطة المستمدة من الخبرة أثناء قيامه بدوده الإثرافي ( عطوي، 2008: 243). دور المشرف يتمثل في العمل على بناء الالتزام الداخلي لدى العاملين

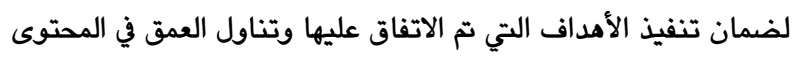
التعليمي من خلال الوظائف الآتية: فهم اللوائح التنظيمية وإحاطة الهيئة التعليمية بكل ماهو جديد فيها، ربط المدرسة بالمجتمع المحلي وإحتياجاته و متطلباته، متابعة العلمية التعليمة و ضبطها وفقا

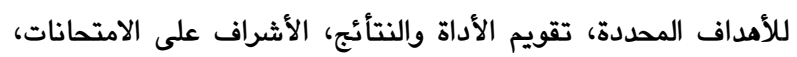
تطوير الخطط المدرسية والمشاركة في اللجان المتخصصة (حسين

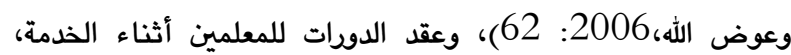
تنظيم اجتماعات مع المدرسين، العمل على تطوير المنهج، المشاركة

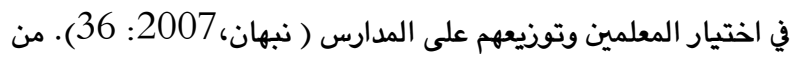
مهام المشرف التربوي الأخرى هو التعرف على شخصية مدير المدرسة، وفاعليته وقدراته ومدى اهتمامه بواجباته الإدارية والتربوية، والتعرف عن كثبعلى علاقة مدير المدرسة بالمعلمين ومدى احترامه لهم

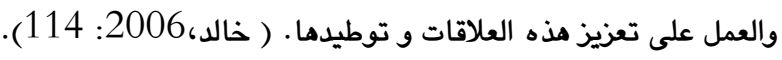
نظريات الإشرافية:حاول كثير من دارسي الادارة التعليمية في السنين الأخيرة تحليل العملية الادارية ويما فيها الاثرافية و وضع نظريات لها، وتختلف هذه النظريات حسب النظرة إلى الطبيعة الإنسانية، في الأنىى

يعرض نماذج من نظريات الإتشرافية: 1 - نظرية دوكلاس ماك كريكور (X,Y): نظرية (X) التقليدية ألتي تفترض أن الانسان بغريزته لايحب العمل، ويحاول التهرب منه بقدر الإمكان، فلذلك معظم الناس يحتاجون إلى الإجبار والضبط والتهديد بالعقاب من أجل حثهم على بذل جهودمم وطاقاتهم لتحقيق

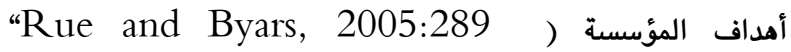

2. مارولدسبيرن: بأنها بيان لأوجه النشاط التي تهتم مباشرة بدراسة وتحسين الظروف التي تحيط بالمعلمين ويتعليم التلاميذ وغيرهم أو تلك العملية المنظمة المخططة الهادفة إلى مساعدة المديرين والمعلمين على بلى اكتساب مهارات تنظيم تعلم الطلاب بشكل يؤدي إلى تحقيق الأهداف التعليمية و التربوية (حسين وعوض الله،2006: 17).

3.3 المشرف التربوي:

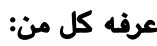
1. (صليوه 2005) بأنه: الأداة الأساسية لعملية الاثراف التربوي لأنه مو الذي يخطط وينفذ العملية الإثرافية كما أنه يوجه نتأئج الإثراف فإذا انصفت بالمواصفات الجيدة نجحت عملية الإثراف وحققت الغرض منها ( صليوه، 2005: 55). 2. وزارة التربية لإقليم كوردستان: بأنه الشخص الذي يوجه و يرشده

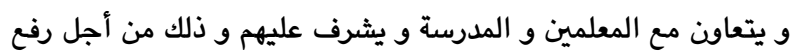

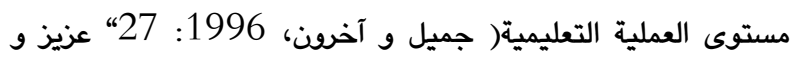

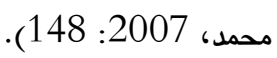

\section{4.خلفية نظرية ودراسات سـابقة:}

1.4 خلفية نظرية: عملية الإثراف التربوي عملية تعاونية تستوجب التعامل مع كل معلم للاستفادة من قدراته، والتصعيد من مهاراته ولتزويده بالبرامج التدريسية اللازمة والعمل على صقل قدراته ما أمكن، ولها أنماط منها الإثراف التعاوني، الإثراف القيادي الديمقراطي، الإثراف السلبي والدبلوماسي، والوقائي، والبنائي، والإبداعي والعلمي والتصميمي، والعيادي( الحريري، 2007: 230). يعتبر جميل و آخرون ( 1996 ) أهداف الاثراف التربوي في إقليم كوردستان بمايلي: العمل على النهوض بجميع المؤسسات التعليمية و تحقيق الإتصال المتبادل بين جميع سلطات التربوية و بين المدرسين و المجتمع المحلي، اعتبار الاثراف أداة لخدمة المعلمين و الجمهور و ذلك من خلال شرح السياسة التعليمية المتبعة في الإقليم و عرض النظريات و الطرائق التربوية الحديثة و نقل الخبرات من المعلمين و المجتمع المحلي و حاجاته و إلى السالطات المسؤولة، والإسهام في تهيئة الوسائل التي تيسر للمعلمين النجاح في تحقيق وسائلهم على نحو يرفع

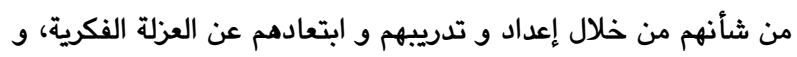
إحترام شخصياتهم حتى يبادر الى الإبتكار و رفع روحهم المعنوية وزيادة حماسه لتحقيق الأهداف التربوية، و العمل على خلق جو من التفاهم و التعاطف و الاحترام المتبادل بين المعلمين و أولياء الامود و

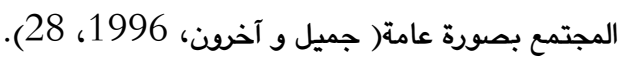
مناك صفات مشتركة تجعل من المشرف، إنساناً تربوياً ممتازاً، منها:

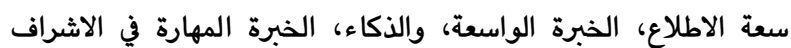


ويتصف هذا المشرف التربوي بالأوتوقراطية والاستبدادية. أما البعد الثاني وهو الاهتمام بالعاملين حيث يشير إلى وجود جو من الود والصداقة والاحترام بين المشرف التربوي والعاملين، ويركز المشرف بـ بـ التربوي امتمامه على إثباع حاجات العاملين وتدقيق رغباتهم وميولهم

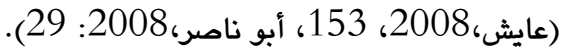
5 - نظرية الشبكة الإدارية لبليل وماوتن: تم بموجبها تقسيم محور الانتاج ومحور العلاقات الإنسانية إلى تسع درجات لينتج (81)

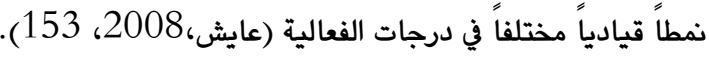
6 - النظرية الموقفية لفدلر: وهي من أحدث النظريات الإدارية وأفضلها وتركز على أن ما يحدث من تغييرات في البيئة الخارجية يجب أن يقابلها تغييرات في البيئة الداخلية، لايوجد ما يمكن اعتباره نمطاً

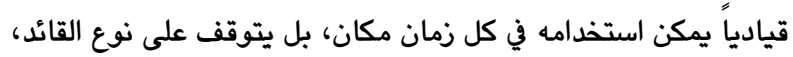

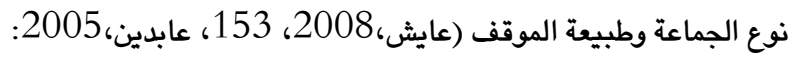

7 - نظرية النظم (The managerial theory): في الاثراف التربوي يشير إلى أن أي تنظيم اجتماعي أو بيولوجي أو

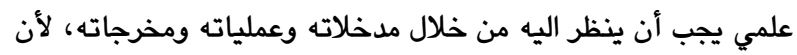
الأنظمة التربوية تتألف من عوامل وعناصر متداخلة متصله مباشرة وغير مباشرة من أفراد النظام، او مع جماعاته الرسمية وغير الرسمية، الاتجاهات السائدة فيه ودافع النظام والعاملين فيه، طريقة بنائه الرسمي، التفاعلات التي تحدث بين تركيباته و مراكزها والسلطة ألتي يشتمل عليها ـ وظهرت النظرية في العقد السادس من القرن العشرين على يد عالم الاقتصاد بولدنج (Bolding) ويولكى (Buckley) عالم الاجتماع. من الامور الدالة على نظمية الاثراف انه يمثل مع مدير المدرسة والمعلم والطالب والمجتمع المحلي شبكه من العلاقات تعمل معاً من أجل تحقيق أهداف مشتركة تتمثل في تحسين عملية التعليم

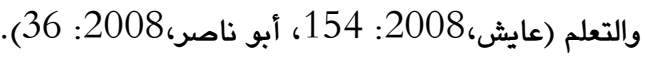
8 - نظرية تالكوت بارسونز (T. Parsons): يرى بارسونز أن جميع المنظمات الاجتماعية يجب أن تحقيق أربعة أغراض رئيسية هي: - التأقلم أو التكيف: بمعنى تكيف النظم الاجتماعية للمطالب الحقيقية للبيئة الخارجية. - تحقيق الهدف: بمعنى تحديد الاهداف وتجنيد كل الوسائل من أجل الوصول إلى تحقيقها. - التكامل: بمعنى إرساء تنظيم مجموعة من العلاقات بين أعضاء التنظيم بحيث تكفل التنسيق بينهم وتوحدهم في كل متكامل. - الكمون: بمعنى أن يحافظ التنظيم على إستمرار حوافزه وإطاره

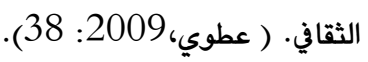

أهداف عملية تقييم الأداء: يمكن اجمال هذا الأهداف بمايلي: متابعة

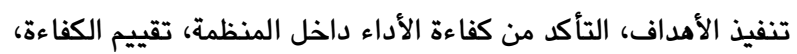
تقييم النتأئج وتحديد مراكز المسؤولية، تحديد مواطن العنف والخلل في منداء
(Yntony and Govindarajan, 2004:649 ). نظرية (Y) التقليدية تؤكد على أن الإنسان بطبيعته يجب العمل لأنه مصدر لإثباع

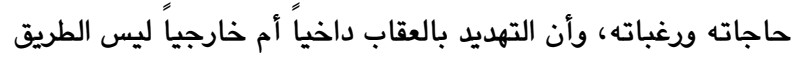
الوحيد للحصول على الجهود اللازمة لتحقيق أهداف المؤسسة، وأن التزام الشخص بالاهداف يعتبر نتيجة للمكافأة المتعلقة بتحقيق تلك الأهداف وأن الإنسان نشيط بطبعته ولديه القدرة على تحمل المسؤولية) Kritner and “Zimmerman, 2003: 185 Gibson, Ivancevich, :60 "Kinicki, 2004: 14 .(Donnely, and Konopaske ,2006 2 - نظرية هاوس (House Theory): تفترض النظرية وجود عوامل موقفية تؤثر في العلاقة السائدة بين القائد و إرضاء المؤوسين وأدائهم، وتتضمن: العوامل الموقفية التي تتعلق بالمرؤوسين مثل بـل القدرة، الحاجة، ومركز الرقابة، وعوامل موقفية تتعلق بالبيئة العملية وتشمل المدى الوظيفي لوظيفة المرؤسوالجماعات ألتي يعمل

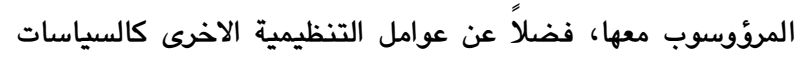
الإدارية والإجراءات والقواعد التنظيمية. (حسين،2006: 144). 3- نظرية ز (Theory Z) أستفاد الأمريكيون من المدرسة

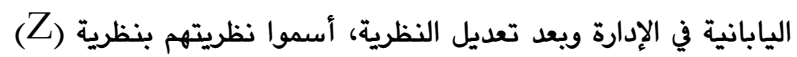
في الإدرة تركز النظرية على مفاهيم ادارية تهدف إلى إحداث تكيف اجتماعي تعاوني مميز بين الأفراد داخل المنظمة، ويشكل يكون متماشيا ومتوافقا مع لفلسفة الادارة ألتي تؤمن بها، ومع القيم الاجتماعية السائدة بين الافراد، التي اكتسبوها وشريوها من المجتمع الذي عاشوا ويعيشون فيه. أن النظرية تنظر إلى المنظمة على أنها سلوك انساني اجتماعي جماعي تندمج فيه أنماط السلوك الفردي في السلوك جماعي كل، على شكل كيان اجتماعي تعاوني متألف منسجم، تذوب فيه المصلحة الشخصية لأكبر حد ممكن، ليحل محلها المصلحة العامة والنضج العام لاعضاء المنظمة وللمجتمع بشكل عام، وهذا الإندماج لايأتي عن الطريق القسر أو الإجبار، بل يأتي من طريق ذرع القناعة في نفوس أعضاء المنظمة بالعمل والجهد الجماعي التعاوني، ويفلسفة ادارية قائمة على أساس النهج الديمقراطي والمشاركة، وأن المنظمة مكان للعمل والحياة معاً، واندماج وانضمار للأهداف الفردية، تشكل أهدافاً جماعية، يسعى الجميع بشكل متعاون متأزر لتحقيقها، فنجاح المنظمة يعني نجاح الجميع والخير والفائدة تعم الكل( عقيلي،-

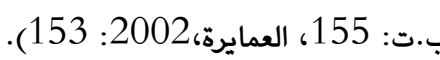
4- نظرية البعدين لاندروهالبن) (two (Andrew Halpin) dimensional theory of leadership) دراسات ميدانية تمت في جامعة ولاية اوهايو سنة (1940)، وأظهرت النتأئج أن هناك بعدين في سلوك القائد من خلال إدارة المؤسسة هما: الاهتمام بالعمل: يشير الى تركيز المشرف التربوي على الانتاجية بالدرجة دون اعتبار للعلاقات الإنسانية لحاجات العاملين وميوليهم 


\section{5نهجية البحث واحراءاته: 5 5}

اعتمد الباحثين المنهج الوصفي من نوع العلاقات الارتباطية القائم على اجراء مسح ميداني لتحديد مجتمع البحث واسلوب اختيار العينة والاداة المستخدمة في قياس المتغير الذي تناوله البحث وطريقة جمع البيانات و الوسائل الاحصائية المستخدمة في معالجة البيانات الواردة في البحث وكما يلي: 1.5

يتألف مجتمع البحث من (34) مشرفاً تربوياً للعام الدراسي (2014 .2015-

2.5 يتالف عينة البحث الحالي وكان منهم (28) مشرف تربوي و مشرف اداري منهم (24) مشرف (4) مشرفة. 3.5 1. وصف الاداة: من اجل تدقيق اهداف البحث استخدم الباحثين مقياس جامز ( فيفر و دنلاب، 2001: 258 ) مكون منهم ( 31 ) فقرة ملحق (1)، حيث يحصل المستجيب من خلال اجابته على المقياس على درجة كلية تعبر عن تقويمه لنفسه و عمله الإثرافي. 2. صدق المقياس:يقصد بالصدق بشكل عام قياس الاختبار او المقياس السمة التي اعد لقياسها ( Gones and George, Gibson , Ivancevich, Donnely, and “2006:427 2006 Konopaske , المقياس اعتمد الباحثين على الصدق الظاهري، ويتم التوصل اليه من خلال تقديرات وأراء مجموعة من الخبراء والمحكمين المتخصصين على درجة قياس المقياس للغرض المعد من اجله (العزاوي، 2007: 94

وعليه تم عرض المقياس على مجموعة من الخبراء و المحكمين في مجال التربية وعلم النفس و الإثراف التربوي من ذوي الخبرة في هذا المجال (الملحق1)، وطلب منهم الحكم على مدى صلاحية فقرات المقياس ويدائله وتعليمات الاجابة مع حذف او اضافة او تعديل ما يرونه مناسباً، و في ضوء تقديرات و آراء و ملاحظات المحكمين اعيد صياغة بعض الفقرات واجريت التعديلات اللازمة على بعضها ،ويلغ صدق للمقياس

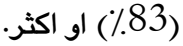

3. ثبات المقياس:يعني الثبات ان يعطي المقياس او الاختبار نفس النتائج تقريبا اذا ما اعيد تطبيقه على نفس الافراد و تحت نفس الظروف أو كيفية المعلومات التي يؤكد على معقولية المعومات و خلوه من أية أخطاء و يبين و يعرض النتائج بمصداقية ( Christensen

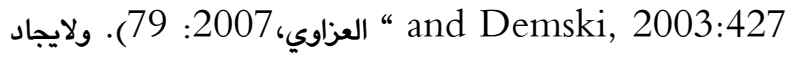
ثبات المقياس طبق الباحثين المقياس على عينة تالفت من (6)
المنشأت والتأكد من كفاءة الخطط الموضوعية و دقة الموازنات التخطيطية. ( البغدادي و العبادي، 2010: 376).

2.4

بعد اطلاع الباحثين على العديد من الدراسات السابقة التي اجريت على التقويم الذاتي للمشرفين لم دراسات مباشرة تناولت الموضوع، لذا عمدا إلى ذكر بعض الدراسات ذات العلاقة بالموضوع للاستفادة من بعض اجراءاتها وخاصة فيما يتعلق بصياغة الاهداف واختيار العينة والوسائل الاحصائية المناسبة والتي يمكن ذكرها بشكل موجز في الجدول وكما ياتي: - الج 1. دراسة البزاز: السنة 1968: الأهداف :تقييم التفتيش الإبتدائي في جامعة بغداد بالعراق، والتعرف على تقييم الإثراف التربوي في العراق

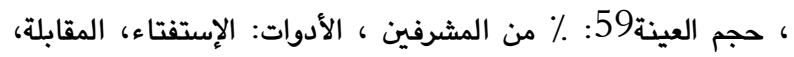

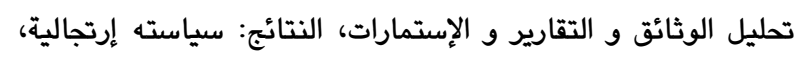
مغلق على نفسه، أسالبيه تقليدية، فقدان النظرة العلمية فيها، متميزة بالمركزية، تتميز صفات المشرفين بالسلبية و غيرعلمية في تقويمهم)

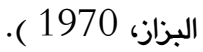

2. دراسة حامد ( 1982 ): تقويم تجربة المشرف المقيم من وجهة ) نظر المشرفين المقيمين و المعلمين، والتعرف على تقويم تجرية المشرف المقيم و تتكون العينة من 78 مشرف مقيم و 352 معلم، و و استخدمت الدراسة استبيان فتكون من(50 فقرة)،وتم استخراج الخصائص السايكومترية، و استخدم الوسائل الإحصائية: نسب المئوية، الوسط المرجح، تحليل التباين، و وصل الى النتائج الآتية: مساهمة التجربة في تحسين العملية التعليمية و رفع مستوى التعليمي و توطيد العلاقات في المدرسة و خارجها و زيادة الإهتمام بمجال الإدارة المدرسية( حامد، 1982 ).

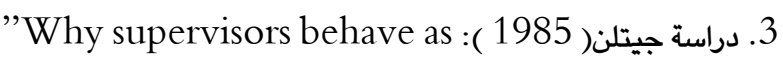
they do: relationship of belief, socialization and استهدفت الدراسة على المقارنة بين المشرفين التربويين practice" العاديين و المشرفين في التربية الخاصة، و العينة كانت مؤلفة من (11مشرفأ تربوياً ) و( 9 مشرفاً من تربية فية الخاصة) واستخدم الإستبيان من نوع ( SCF )، المقابلات، التسجيل الصوتيطريقة ايزونر و والاسلجمع البيانات، و الإختبار X2، النسبة المئوية، معامل مكنيمار، معامل التوافق كوسائل الإحصائية، و وصلت الى النتائج التالية: تطابق الأهداف التربوية للمشرفين مع النتائج يركز عليها المشرفين و التأكيد على الحاجات الإجتماعية و الجلسات الإثرافية و نمو المهارات المعرفية و أهمية دور العلاقات الإجتماعية و فرضيات

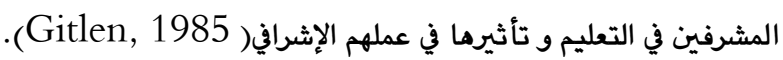


تم الاستعانة بالوسائل الاحصائية الاتية في معالجة البيانات: 1. معامل ارتباط بيرسون: استخدم لاستخراج الثبات بطريقة اعادة الاختبار (عباس واخرون، 2007: 308). 2. الاختبار التائي لعينة واحدة: وذلك لاختبار دلالة الفرق بين التموسط النظري و المتوسط المتحقق للمقياس (العتوم،2008: 390). 3. الاختبار التائي لعينتين مستقلين: تم استخدامه لمعرفة دلالة الفرق الاحصائي تبعاً لمتغيرات الجنس (ذكور ، اناث) والشهادة الأكاديمية (دبلوم، بكالوريوس) وحسب متغير التخصص (التربوي، الإداري)

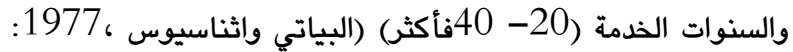
.(260-254

\section{6. عرض النتائج و مناقشتها}

سيتم عرض النتائج وفقا لأهداف البحث وكما يأتي : الهدف الاول: ما مستوى التقويم الذاتي لدى المشرفين التربويين و الاداريين في مركز زاخو؟

مشرفين تريويين، ثم اعادا تطبيق المقياس على نفس الافراد بعد مرود اسبوعين تقريبا من التطبيق الاول، و باستخدام معامل الارتباط بيرسون في المعالجة الاحصائية ، تبين ان قيمة الارتباط بين نتائج التطبيق الاول و الثاني تساوي (80\%) وهو معامل ثبات يمكن الاعتماد

عليه.

4.5 تطبيق المقياس:

بعد الانتهاء من اجراءات الصدق و الثبات و الحصول على المقياس بصورته النهائية، ثم اختيار عينة مناسبة بلغت (28) مشرف تربوي و مشرف اختصاصي غير تلك المشمولين بعينة الثبات، و طبقوا عليهم المقياس و تم التطبيق في (2015/6/10). 5.5 تصحيح المقياس: لأن للمقياس خمسة بدائل و هي (دائماً ، غالباً ، أحياناً، نادرآ، أبداً) فقد اعطي لكل بديل ونن ( 5، 4، 3 ، 2، 1، 1) في حالة الفقرات الايجابية وعلى التوالي، وتعكس الأوذان في حالة الفقرات السلبية. 6.5 الجدول 1: نتائج الاختبار التائي للفروق بين المتوسط الحسابي و المتوسط النظري لمستوى التقويم الذاتي

\begin{tabular}{|c|c|c|c|c|c|c|c|c|c|c|}
\hline \multirow[t]{2}{*}{ عند } & الدلالة & درجة الحرية & التائية & القيمة & التائية & القيمة & المتوسط & الانحراف & المتوسط & لعدد \\
\hline & مستوى0.05 & & & الجدولية & & المحسوية & النظري & المعياري & الحسابي & \\
\hline & دالة & 27 & & 1.708 & & 6.491 & 155 & 16.800 & 113.61 & 28 \\
\hline
\end{tabular}

الباحثين ذلك إلى أن اغلب المشرفين التربويين و الإختصاصيين ذو خبرة و تجربة علمية في الأشراف و ذلك لأنهم من خريجي كليات التربية و المعاهد المعلمين و المعلمات او خريجي دورات تأهيلية و تربوية، يتعلمون فيها طرائق التدريس واساليب التعامل مع الطلبة و المعلمين، فينعكس ذلك على سلوكياتهم في عملهم الإثرافي من جانب و تقويمهم الإثرافي لذواتهم و للمعلمين الذين تحت إثرافهم.

(4.349) وعند اختبار معنوية الفرق بين متوسطات الذكور و الاناث باستخدام الاختبار التائي لعينتين مستقلتين تبين ان القيمة التائية المحسوية بلغت (2.10) وهي اقل من القيمة الجدولية البالغة

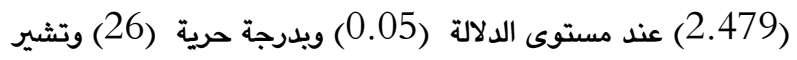
هذه النتيجة إلى عدم وجود فرق ذي دلالة احصائية في مستوى التقويم الذاتي لدى المشرفين والمشرفات الإداريين والاختصاصيين تبعاً

لمتغير الجنس كما موضح في الجدول (2).
اوضحت نتائج البحث إلى ان المتوسط الحسابي لمجموع افراد عينة البحث بلغ (113.61) درجة ويانحراف معياري قدره (16.800) درجة والمتوسط النظري (155) وياستخدام الاختبار التائي (t.test) لعينة واحدة تبين ان القيمة التائية المحسوية بلغت (6.491) وهي أعلى من القيمة التائية الجدولية البالغة (1.708) عند مستوى دلالة(0.05) ويدرجة حرية (27)، وتشير مذه النتيجة إلى وجود مستوى ايجابي من التقويم الذاتي لدى أفراد عينة البحث، و يعزى الهدف الثاني: هل هناك فرق ذات دلالة إحصائية في مستوى التقويم الذاتي لدى المشرفين الاداريين والاختصاصيين في مدينة زاخو حسب المتغيرات الاتية: • الجنس (ذكور-اناث).

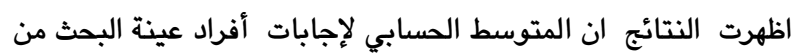

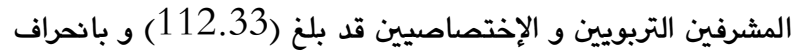
المعياري قدره ( 17.805) في حين بلغ المتوسط الحسابي لافراد عينة البحث من المشرفات (121.25) ويانحراف المعياري قدره الجدول2: نتائج الاختبارالتائي للفروق بين متوسط درجات الطلبة بحسب متغيرالجنس

\begin{tabular}{|c|c|c|c|c|c|c|c|c|c|c|}
\hline \multirow[t]{2}{*}{ عند } & الدلالة & درجة الحرية & التائية & القيمة & التائية & القيمة & الانحراف & الوسط & العدد & الجنس \\
\hline & مستوى0.05 & & & الجدولية & & المحسوبة & المعياري & الحسابي & & \\
\hline \multirow{2}{*}{\multicolumn{2}{|c|}{ غير دالة }} & 26 & & 2.479 & & 2.10 & 17.805 & 112.33 & 24 & ذكور \\
\hline & & & & & & & 4.349 & 121.25 & 4 & اناث \\
\hline
\end{tabular}


(112.50) ويانحراف معياري قدره (15.685) وعند اختبارمعنوية الفرق بين متوسط درجات زائدة الشهادة دبلوم ويكالوريوس باستخدام الاختبارالتائي لعينتين مستقلتين تبين ان القيمة التائية المحسوية تساوي (0.461) وهي اقل من القيمة التائية الجدولية البالغ (2.479) عند مستوى دلالة (0.05) و بدرجة حرية (26) وتشير هذه النتيجة إلى عدم وجود فروق ذي دلالة احصائية بين متوسط درجات الاختصاص الانساني و العلمي و كما موضح في الجدول (3). الجدول 3: نتائج الاختبار التائي لدلالة الفروق بين متوسط درجات ولات الطلبة بحسب متغير الشهادة دبلوم- بكالوريوس

مذا يعني ليس مناك فرق ذات دلالة احصائية بين تقويم لذواتهم حسب متغير الجنس، وقد يرجع إلى أن كلا الجنسين راضين عن أنفسهم وعملهم الإثرافي، لكونها يقومون بنفس العمل و لهم نفس الإمتيازات المادية و المعنوية و الإدارية.

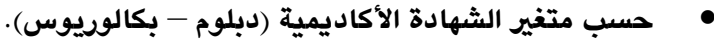

اظهرنتائج البحث ان الوسط الحسابي لأفراد عينة البحث من شهادة الدبلوم قدبلغ (115.60) ويانحراف معيار قدره (19.369) في حين بلغ الوسط الحسابي لافراد عينة البحث من شهادة البكالوريوس

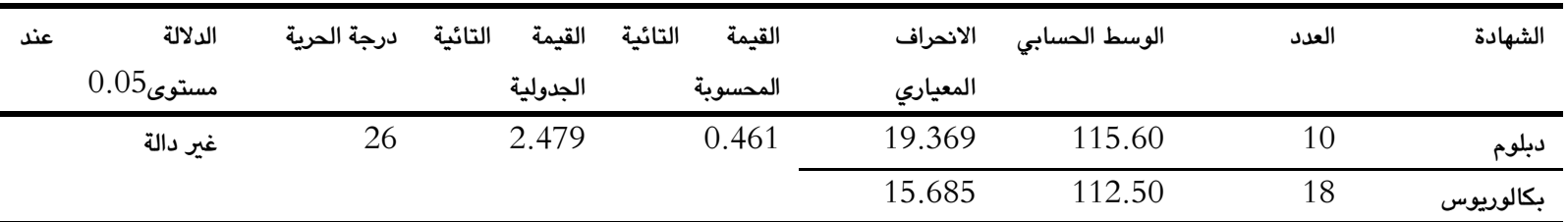

حين بلغ الوسط الحسابي لأفرادعينة البحث من تربوي اختصاص( 114.56) ويانحراف معياري قدره (16.621) وعند أختبار معنوية الفروق بين متوسط درجات الصفين وياستخدام الاختبار التائي لعينتين مستقلتين تبين ان القيمة التائية المحسوية تساوي ( 0.862) وهي أقل من القيمة التائية الجدولية البالغة (2.479) عند مستوى الدلالة (0.05) بدرجة الحرية (26) وتشير هذه النتيجة إلى عدم وجود فروق ذي دلالة احصائية بين متوسط درجات الصفين وكما موضح في

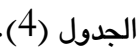

قد يعزى ذلك إلى ان جميع المشرفين التربويين و الإختصاصيين يشاركون الدورات التدريبية يتدريون على مهارات العمل الفعال و ينعكس ذلك على سلوكياتهم الإثرافية بنفس النسبة، يعني ذلك أن لنوعية الشهادة الأكاديمية ليس لها تأثير في تقويم المشرفين لذواتهم، لذلك نرى أنهم يقومون أنفسهم بصورة متشابهة. • عسب متغير اختصاص ( التربوي- الإداري). أضهرت نتائج البحث ان الوسط الحسابي لأفراد العينة البحث المهنة الإداري قد بلغ (105.67) ويانحراف معياري قدر ( 19.732) في

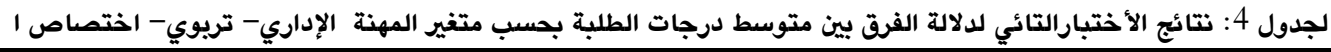
المهنة مستوى0,05

\begin{tabular}{|c|c|c|c|c|c|c|c|}
\hline & & & & & & & \\
\hline & & الجدولية & المحسوبة & & & & \\
\hline غير دالة & 26 & 2.479 & 0.862 & 19.732 & 105.67 & 3 & الإداري \\
\hline & & & & 16.621 & 114.56 & 25 & التدريسي \\
\hline
\end{tabular}

• • • للتحقيق من هذا الهدف استخرج الباحثان المتوسط الحسابي و

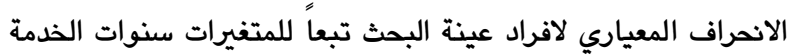

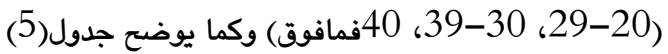

ويعزى ذلك إلى ان جميع المشرفين التربويين و الإختصاصيين ضمن عملهم الإثرافي يواجهون نفس الصعويات و المشاكل و الحالات و ينعكس ذلك على سلوكياتهم الإثرافية بنفس النسبة، يعني ذلك أن لنوعية الإختصاص الإداري أو التدريسي ليس لها تأثير في تقويم المشرفين لذواتهم، لذلك نرى أنهم يقّومون أنفسهم بصورة متشابهة. الجدول 5: يبين فئات سنوات الخدمة و عدد المشرفين لكل فئة

\begin{tabular}{|c|c|c|c|}
\hline النصراف المعياري & عينة & متوسط & سنوات الخدمة \\
\hline 17.963 & 14 & 109.07 & $29-20$ \\
\hline 16.627 & 11 & 117.45 & $39-30$ \\
\hline 5.508 & 3 & 120.67 & 40-فما فقق \\
\hline 16.800 & 28 & 113.61 & Total \\
\hline
\end{tabular}


لجدول 6: ثم طبق الباحثان تحليل تباين ذو اتجاه واحد Anova، و أدناه النتائج

\begin{tabular}{|c|c|c|c|c|c|c|}
\hline \multirow{3}{*}{ مستوى $\quad$ الدلالة 05} & القيمةالتائية & القيمةالتائية & \multirow{3}{*}{ المجموع المربعات } & \multirow[t]{3}{*}{ درجة الحرية } & \multirow{3}{*}{ المجربعات المجوع } & \multirow[t]{3}{*}{ سنوات الخدمة } \\
\hline & & & & & & \\
\hline & الجدولية & المحسوبة & & & & \\
\hline \multirow[t]{3}{*}{ غير دالة } & 3.39 & 1.069 & 19.732 & 2 & 600.356 & بين السنوات \\
\hline & & & 16.621 & 25 & 7020.323 & داخل السنوات \\
\hline & & & & 27 & 7020.679 & الكلي \\
\hline
\end{tabular}

4. ضرورة قيام المشرفين ببناء جسور التواصل الاجتماعي و الإنساني و إيجاد نقاط التلاقي بين مكونات العلمية التعليمية و الإدارية في المدرسة لحصول نتائج أفضل. 5. ينبغي أن يكون هناك فلسفة تربوية لدى المشرفين التربويين في المدارس مبنية على استراتيجية تتضمن تنمية التفاهم و التناسق و التسامح و الصداقة و الشعور بالمسؤلية بين المدرسين و المعلمين و الإداريين تجاه عملهم التربوي و التعليمي ، لتمكينهم من مواجهة التحديات التي تواجهه المجتمع الكوردستاني في القرن الحادي و العشرين و خاصة الإرهاب و التعصبية الهمجية و العولمة و عصر

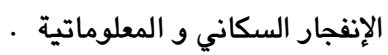

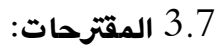

استكمالاً للفوائد المتوخاة من البحث نقترح إجراء: 1. دراسة لتحديد الصعويات التي تواجه المشرفين التربويين و الجراه المشرفين الإختصاصيين في العملية الإثرافية في مركز قضاء زاخو. 2. دراسة مماثلة عن تقويم المشرفين التربويين و المشرفين الإختصاصيين من قبل معلمين و مدرسين مرحلة التعليم الاساسي و الإعدادي ومقارنة نتائجها مع نتائج البحث الحالي. 3. دراسة مماثلة عن الشعور بالمسؤولية لدى المشرفين التربوييَن و المشرفين الاختصاصيين وعلاقتها بمتغيرات اخرى غير تلك التي تناولها البحث الحالي (سنوات، الحالةالاجتماعية، الموقع الجغرافي (الخ

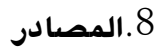

( 2015 ). راثؤرتةك لدؤر نئنجاميَن تاقكرنيَن قوتابييَن قؤناغينَ دؤماهيَّ ل قوتابخانةيَنَ بنةرةت و و ئامادةيى، رؤذناما ئتظرؤ، ذمارة ( 1685)، بةرثةرِ ( 13 ) ) ل ( 2015/7/12

محةمةد، سةحةر ( 2015 ). راثؤرتةك لدؤر تاقيكرن و ئَنجاميَن تاقيكرنى ل سالا

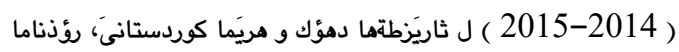
وار، ذمارة ( 1369 ) بةرثةرِ ( 12 ) ل ل ( 2008 (2015/7/12).

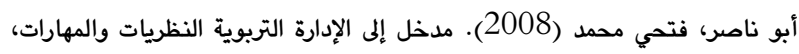

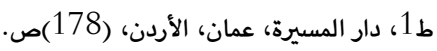

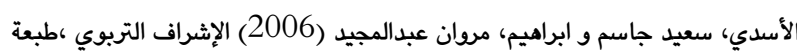
الاولى/الاصدار الثاني،دارالثقافة، عمان :الاردن.
ويعزى ذلك إلى ان جميع المشرفين التربويين و الإختصاصيين ضمن عملهم الإثرافي يواجهون نفس الصعويات و المشاكل نلاحظ الجدول اعلاه ان القيمة التائية المحسوية بلغت (1.069) وهي اقل من باقيمتها الجدولية البالغة (3.39) عند مستوى دلالة (0.05) و درجة الحرية (25-2) وهذا عدم وجود فرق حسب متغير سنوات الخدمة لدى المشرفين حول تقويمهم الذاتي، ويعزى الباحثين ذلك لدور عامل سنوات الخدمة للمشرفين والمشرفات التربويين و الإداريين ليس لها تأثير في تصورهم عن ذواتهم و عملهم الإثرافي، و ذلك لأن جميع فئات الخدمة يتعاملون نفس الأفراد و المدراء و المعلمين و المدرسين مما يحملون على نفس الاتجاه نحو عملهم الإثرافي و ينعكس ذلك على ولى عملهم بنفس المستوى لدى جميع الفئات الخدمة. 7.الاستنتاجات والتوصيات والمقترحات

وفي ضوء نتائج البحث تم التوصل إلى مجموعة من الاستنتاجات و التوصيات والمقترحات وكما يأتي: 1.7 1.7 الاستنتاجات: 1. وجود مستوى إيجابي للتقويم المشرفين و المشرفات التربويين و الإختصاصيين لذواتهم. 2. عدم وجود فروق ذات دلالة إحصائية بين التقويم الذاتي للمشرفين و المشرفات التربويين و الإختصاصيين وفقاً لمتغيرات البحث الحالي: الجنس، الشهادة، التخصص، والسنوات الخدمة، و يرى الباحثين أن لمتغيرات البحث الحالي ليس لها تأثير في عمل المشرفين التربويين و الإختصاصيين، لأن لعمله الإثرافي طبيعة متشابهة بالنسبة ليسي

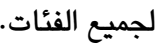

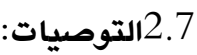
1. زيادة الاهتمام بواقع المشرفين و المشرفات التربويين و واتوال

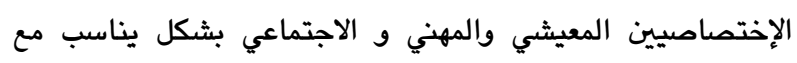
مكانتهم الاجتماعية و الرسالة التي يحملونها، نظراً لدورهم الأساسي

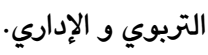
2. التأكد على ضرورة متابعة القائمين بالعملية الإثرافية حول كيفية القيام بواجباتهم و المهام الموكلة اليهم. 3. ضرورة فتح دورات تدريببية و توجيهية تطبيقية أكثر للمشرفين بخصوص المسؤولية وأداء المهام الموكلة اليهم بأفضل شكل ممكن. 
زانكؤيا دهوك ( مرووظايةتى ) ، ثةربةندا (10) هذمارا (2)، (-145

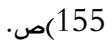

عطوى، جودت عزت(2008). الإدارة التعليمية والإشراف التربوي أصولها

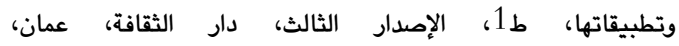

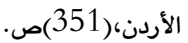

عقيلي، عمر وصفي (ب.ت. ). مبادىء في الادارة 1 ، جامعة العلاقات الدولية سانت

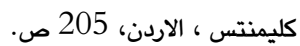

عيسان، صالحة عبدالله، وعطاري، عارف توفيق، والعاني، وجيهة ثابت (2007).

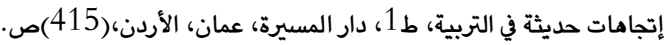

الغزاوي، رحيم يونس كرو(2007) القياس و التقويم في عملية التدريسية ، الطبعة الاولى، دار الدجلة ،بغداد ،العراق.

العمايرة، محمد حسن (2002). مبأدئ الإدارة المدرسية، ط3، دار المسيرة، عمان، المان المان

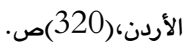

فيفر، ايزابيل و جين دنلاب ( 2001 ). الإثراف التربوي على المعلمين ، دليل

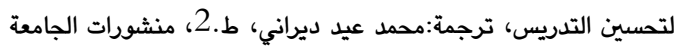
الأردنية، عمان: الأردن.

كه لهور، نوزاد ( 2004). أهمية التربية الخاصة في تقدم المجتمع، مجلة آفاق الاقدرن التربوية، دورية تصدرها وزارة التربية في أقليم كوردستان، العدد) 2 2)،

$$
\text { كانون الثاني، } 2004 .
$$

محمد،محمد جاسم (2008) سايكلوجية الادارة التعليمية و المدرسية و آفاق التطوير الثاني،

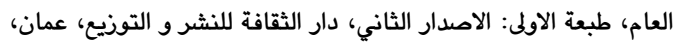

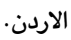

نبهان، يحيىى محمد(2007). الإثراف التربوي ( بين المشرف، المدير، المعلم )،

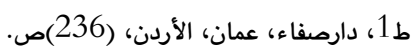

Antony, Robert N. and Goviandarajan Vijay ( 2004 ). Management control systems, $11^{\text {th }}$ ed., McGraw Hill Irwin, 851pp.

Byrne, Robert and Baron, Donn( 1997 ). Social psychology, $8^{\text {th }}$ ed. Allyn and Bacon, $640 \mathrm{pp}$.

Christensen, John A. and Demski,Joel S. (2003). Accounting theory, an information countent perspective, McGraw-Hill, Irwin, 465pp.

Gibson, James ,Ivancevich, John, Donnely, James H., and Konopaske, Robert (2006). Organizations, behavior's structure, processes , $12^{\text {th }}$ ed. McGraw-Hill, Irwin ,606pp.

Gitlin, Andrew and et al (1985). "why supervisors behave as they do: relationship of belief , socialization and practice", journal of education for teaching (JET), vol. 11, no. 1.

Jones, Gareth R. , George , Jenifer M. ( 2006 ). Contemporary management, $4^{\text {th }}$ ed. McGrawHill, Irwin, ( 780 ) pp.

Ivancevich, John m., Konopaske, Robert and Matteson, Micheal (2005). Organizational behavior and management , $12^{\text {th }}$ ed. McGraw-Hill, Irwin ,707pp.

Kreitner, Robert and Kinicki, Angelo ( 2004). Organizational behavior, $6^{\text {th }}$ ed. McGraw-Hill, Irwin ,710pp.

Rue, Leslie W. and Byars Lloyd L. ( 2005 ). Management $\&$ application, $11^{\text {th }}$ ed. McGraw Hill, NY.

Zimmerman, Jerold ( 2003). Accounting for decision making and control, $4^{\text {th }}$ ed., McGraw Hill Irwin, 764pp.
باقر، عبدالكريم محسن و حمزة، كريم محمد (1984) .علم النفس

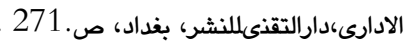

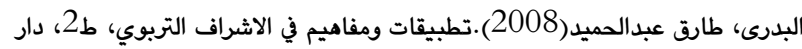

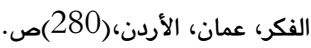

البزاز، حكمت عبدالله ( 1970 ). تقييم التفتيش الإبتدائي في العراق، جامعة بغداد، الأرد،

مطبعة الإرثاد، ( رسالة ماجستير غير منشورة ).

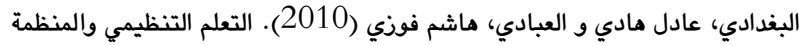

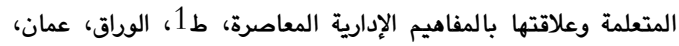

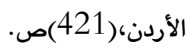

البياتي، عبدالجبار توفيق و زكريا زكي اثناسيوس (1977) الأردن، الاحصاية الوصفي

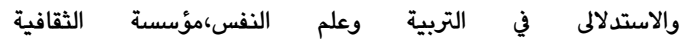

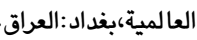

جرجس، جرجس ميشال (2005). معجم مصطلحات التربية والتعليم، ط1، دار النهضة العربية، بيروت، لبنان، (600)ص.

جميل، ناظم دمام واخرون (1996). دليل المشرف التربوى، طبعة وذارة التربية/

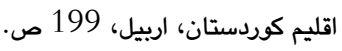

حامد، فرحان رشيد ( 1982 ). تقويم تجربة المشرف المقيم من وجهة نظر

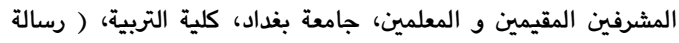

$$
\text { ماجستير غير منشورة). }
$$

الحريرى، رافدة عمر ( 2007 ). إعداد القيادات الإدارية لمدارس المستقبل في ضوء

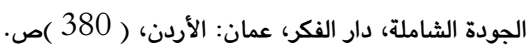

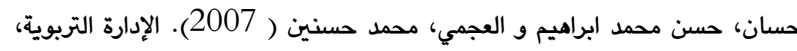

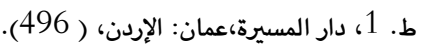

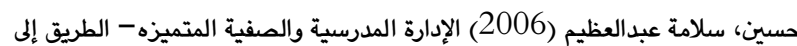

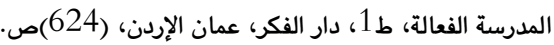

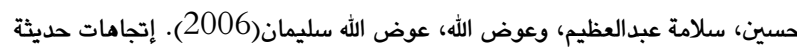

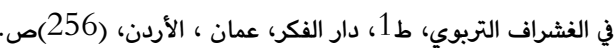

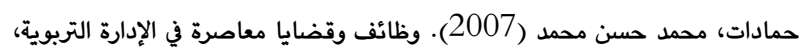

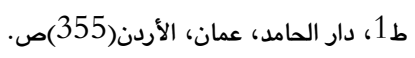

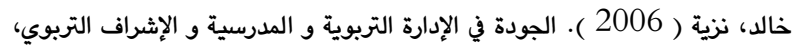

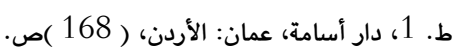

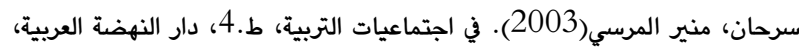

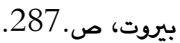

صليوة، سهى نونا ( 2005 ). الإثراف و التنظيم التربوي، ط. 1، دار صفاء، عمان:

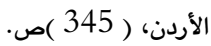

عابدين، محمد عبدالقادر(2005). الإدارة المدرسية الحديثة، ط2، دارد، دار الشروق،

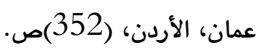

عايش، أحمد جميل (2008). تطبيقات في الاشراف التربوي، ط1، دار، الارد، المسيرة،

$$
\text { عمان، الأردن، (334)ص. (2008) تصليقات }
$$

عباس،محمدخليل واخرون(2007).مدخل الىمنهج البحث في التربية وعلم النفس الاردن، (دم) الطبعةالاولى،دارالمسيرة للنشرورالتوزيع،عمان،الاردن.

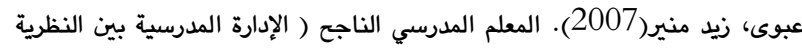

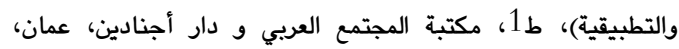

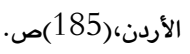

العتوم، شفيق احمد(2008) طرق الاحصاء باستخدام spss ،طبعة الثالثة،دار

$$
\text { المناهج للنشر و التوزيع، عمان، الاردن. }
$$

عزيز، عمر ابراهيم و محمد، نصرالدين ابراهيم (2007). تقويم عمل المشرفين الاردن التمنين التربويين من وجهه نظر المعلمين النخبة ومقترحاتهم لتطويره، طوظارا 
ملحق 1

المحترم/ المحترمة

استبيان
إقليم كوردستان- العراق

وزارة التعليم العالي والبحث العلمي

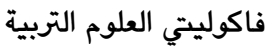

جامعة زاخو - قسم علم النفس

الاخ/الاخت: المشرف التربوي او الإداري. تحية طيبة.

يقوم الباحثان بدراسة موسوم ( تقويم الذاتي للمشرفين التربويين و الإداريين في مركز قضاء زاخو ) وقد استخدم مقياس ( فيفر و دنلاب، 2001،

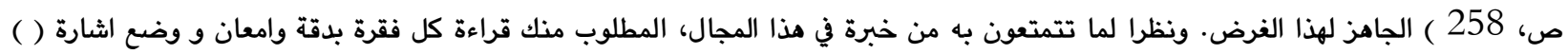

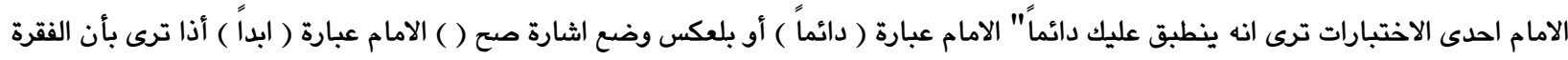
لاينطبق عليك ( ابداً ). أن اجابتك الصريحة و الصادقة على جميع. وتقبلوا فائق شكر البحثان واحترامه

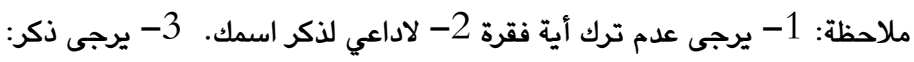

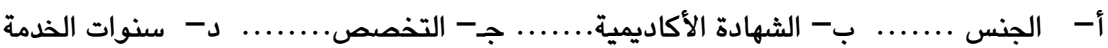

الباحث

الباحث

د.نصرالدين ابراهيم محمد

م· بيوار طه شكري

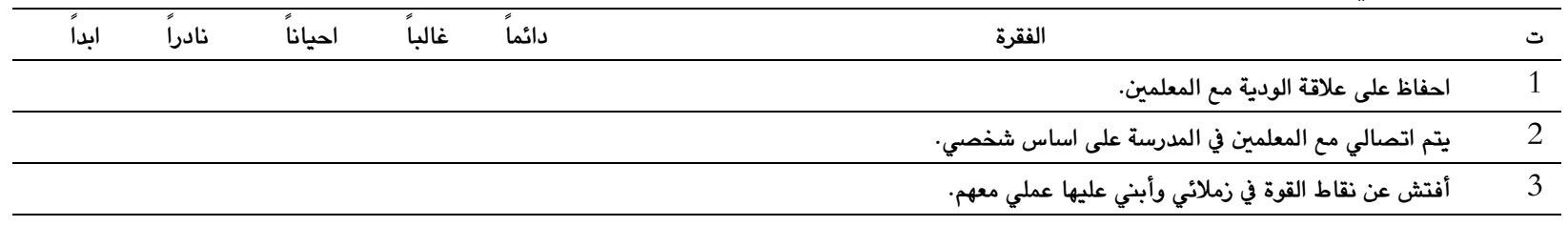

4

مستواهم العلمي والتربوي.

أتقبل أسهاماتهم مهما بدت غير مهمة.

6

7

8

9

10

11

12

أسهل على المعلمين والطلبة مشاركتهم في رحلات ميدانية تريوية.

خططي الاشرافية واقعية ومحددة.

توافق خططي الاشرافية مع طموحات الجهاز التعليمي والمواطنين في المجتمع المحلي.

16 ت 16

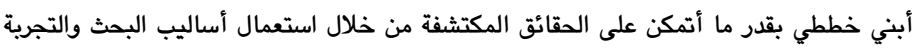

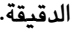

أستشير الاباء في ما يعتقدون ان على المدرسة أن تفعله. 18

أسهم في جهود المؤسسات والوكالات الموجودة في المجتمع المحلي التي تهتم في التطوير التربوي التهاء 


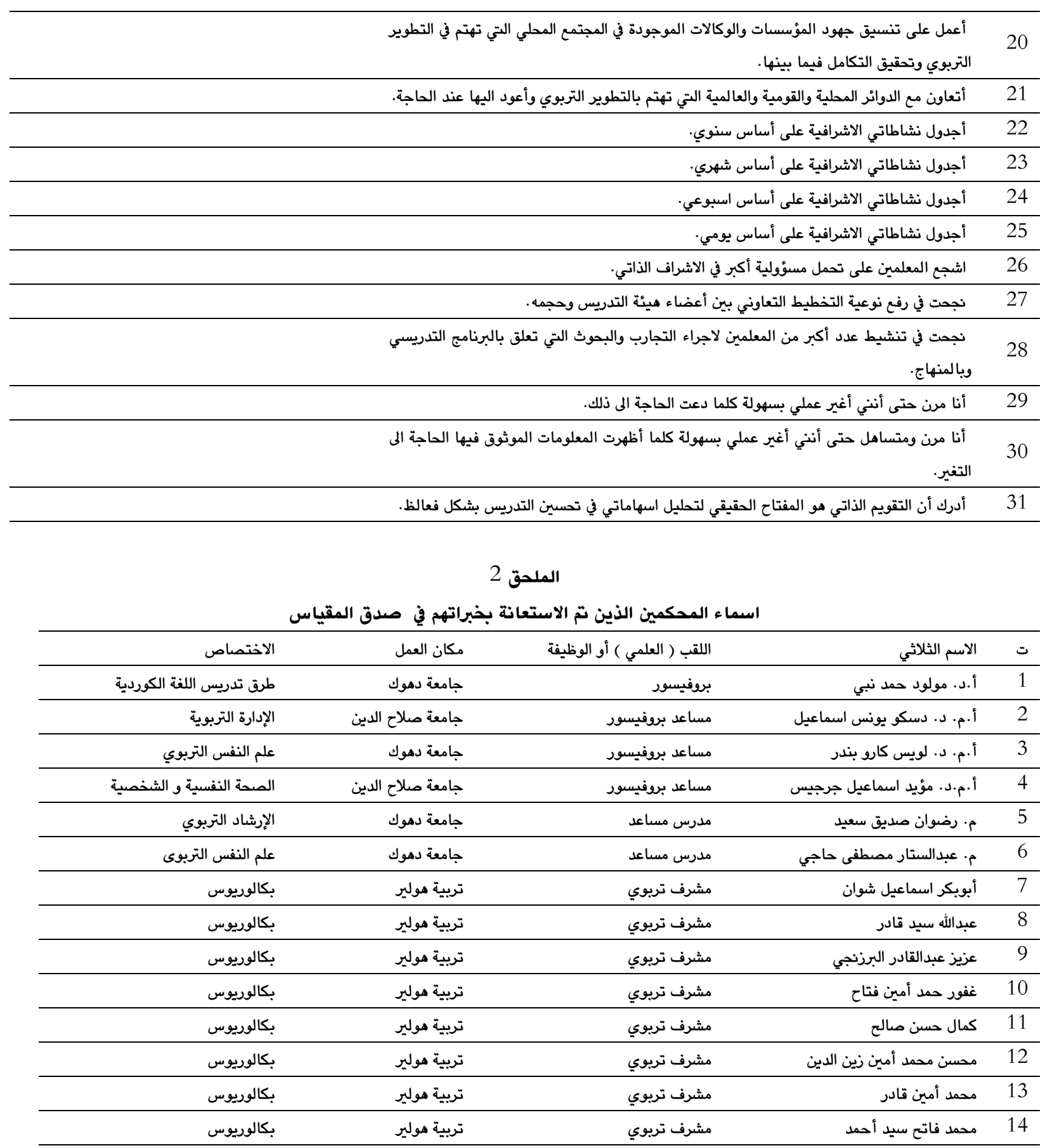




\title{
هـلسهنكاندنا خويهتى لنك سهريـهرشتيِّن يِهوهردهى وكاركيّرى ل سهنتهرى قهزا زاخو
}

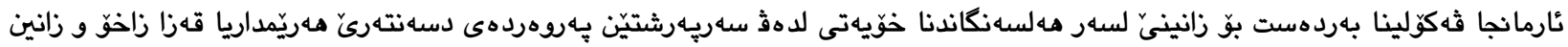

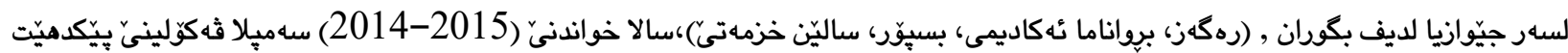

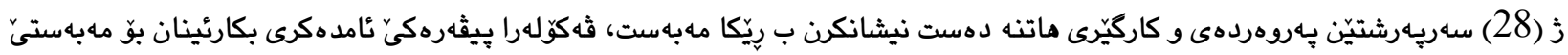

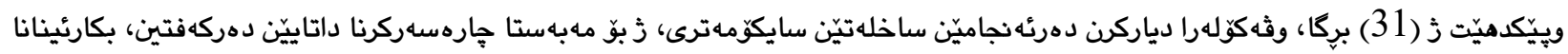

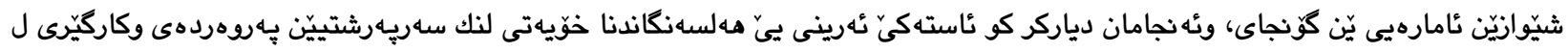

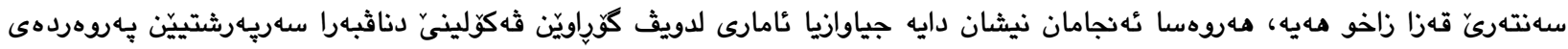

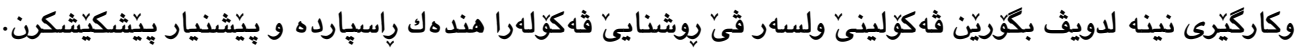

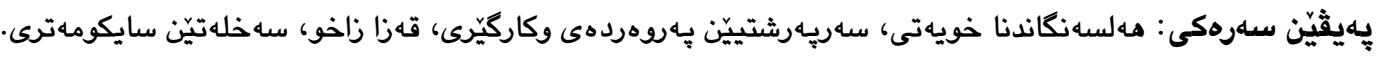

\section{SELF-EVALUATION OF EDUCATIONAL AND ADMINISTRATIONAL SUPERVISORS IN THE CITY OF ZAKHO}

\begin{abstract}
:
The aim of study is to testify the statistical hypotheses concerning the significant differences among supervisors in the city of Zakho according to the variables of the study in the academic year (2015/2014) in self-evaluation. The population and the sample of the research consists of (28) supervisors in the city of Zakho. The researchers used the interview and questionnaire which includes of (31) items. The results of the research showed that supervisors have a significant meaningful self- evaluation toward themselves and their function; also there is no statistical significant differences among them according to the variables of gender, diploma, age and years of service. The study presented some suggestions and recommendations in the light of results.
\end{abstract}

Keywords: Self-evaluation, Educational and administrational supervisors, City of Zakho, Psychometric properties. 